\title{
Factors related to burnout in resident physicians in Japan
}

\author{
Yoshito Nishimura, Tomoko Miyoshi, Mikako Obika, Hiroko Ogawa, Hitomi Kataoka, \\ Fumio Otsuka
}

Department of General Medicine, Okayama University Graduate School of Medicine, Dentistry and Pharmaceutical Sciences, Okayama, Japan

Correspondence: Yoshito Nishimura, Department of General Medicine, Okayama University Graduate School of Medicine, Dentistry and Pharmaceutical Sciences, Okayama, Japan. Email: me421060@s.okayama-u.ac.jp

\begin{abstract}
Objectives: We explore the prevalence and characteristics of burnout among Japanese resident physicians and identifies factors associated with burnout.

Methods: A cross-sectional study was conducted three times between April 2017 and March 2018 at a Japanese teaching hospital. Resident physicians were invited to answer an online survey that included existing valid instruments related to burnout, depression, and empathy. Demographic, background, occupational, and socioeconomic data were also collected. Participants were prompted to report the average daily work hours and the specialty they wish to pursue.

Results: Overall, 39/76 (51\%), 27/76 (36\%), and 21/76 (28\%) resident physicians responded to surveys in April 2017, October 2017, and March 2018, respectively. The percentages of participants with burnout for surveys in April 2017, October 2017, and March 2018 were 7/39 (18\%), 6/27 (22\%), and 7/21
\end{abstract}

(33.3\%). Emotional exhaustion (EE) was the only burnout component strongly correlated with the severity of depression $(\mathrm{r}=.615, \mathrm{p}<.001 ; \mathrm{r}=.706, \mathrm{p}<.001 ; \mathrm{r}=.601, \mathrm{p}<.01)$. $\mathrm{EE}$ and depersonalization (DP) had no significant correlation with average daily working hours $(\beta=.156, p=.343$ for EE; $\beta=.061, \mathrm{p}=.711$ for DP).

Conclusions: The results suggest that capping working hours alone may not be effective in reducing burnout in Japanese resident physicians. Medical educators might need to consider not only working hours but also individual job quality and satisfaction to address burnout. Future studies may need to incorporate qualitative methods to explore the characteristics of burnout.

Keywords: Burnout, empathy, residency training, work style reform, overtime hours

\section{Introduction}

Burnout is a chronic psychological condition characterized by a loss of enthusiasm, feelings of physical and mental exhaustion, depersonalization, and a reduced sense of personal accomplishment. ${ }^{1}$ Burnout is known to be prevalent among physicians, who are constantly burdened with an enormous amount of stress and responsibility. ${ }^{2}$ In fact, estimates from the United States and European countries indicate that the prevalence of burnout may exceed $50 \% .{ }^{3}$ Resident physicians are especially vulnerable to burnout when they are new to their working environment and are exposed to pressure from senior colleagues.-10 In addition, physician burnout can increase the rate of medical errors, lead to suboptimal patient care, and reduce empathy. Following previous reports, researchers have been striving to pinpoint its prevalence and

geographical characteristics in order to design possible countermeasures. ${ }^{11-17}$

The postgraduate residency training system in Japan is characterized by a national matching system and a two-year clinical training program. During this program, residents rotate through different specialties, which may require them to move to different facilities. This differs from the system in the United States, wherein residents complete three to six years of clinical training after choosing a particular specialty. It is more similar to the system in place in the United Kingdom, where all medical graduates must participate in general practitioner training as their postgraduate training. The unique qualities of Japan's medical residency system, particularly with regard to its sources of stress, suggest that the 
characteristics and associated factors of burnout might differ between Japanese residents and those of other countries.

Some scholars have proposed that burnout tends to overlap with depression, although their relationship remains unclear. ${ }^{5,18-21}$ It was reported that $6-7 \%$ of Japanese people are depressed, ${ }^{22}$ which is substantially lower than the $25.2 \%$ reported among Japanese resident physicians. ${ }^{23}$ Taking these results together with the high burnout rates among Japanese resident physicians, we can expect a higher rate of overlap between burnout and depression in the participants as well. Despite the urgent need to determine the prevalence of burnout in Japanese resident physicians, there are comparatively few studies on this topic, with the latest being published in $2016 .{ }^{24}$ It is important to update our knowledge of the prevalence and any contributing factors of burnout in resident physicians, particularly in light of the work reforms introduced by the Japanese Ministry of Health, Labour and Welfare (MHLW) in 2017. The draft of work reform plan included capping overtime work; ${ }^{25}$ however, it remains unclear whether mere work hour restrictions are effective in preventing burnout.

In this study, we aimed to reveal the up-to-date prevalence, characteristics, and contributing factors of burnout among Japanese resident physicians with special focus on work hours.

\section{Methods}

\section{Design and study participants}

We performed cross-sectional surveys between April 2017 and March 2018. Questionnaires were administered in April 2017 (Time 1), October 2017 (Time 2), and March 2018 (Time 3). Participants were the postgraduate year (PGY) 1 and 2 resident physicians at Okayama University Hospital, in Okayama, Japan. This is a university hospital with 813 beds. We distributed a self-administered online survey to all PGY 1 and 2 resident physicians (76 people) in a single Japanese university hospital through an e-mail invitation. No financial incentives were given for their participation. This study protocol was approved by the institutional review board of Okayama University Hospital. The participants' consent was implied by their return of the questionnaires.

Of the 76 resident physicians, 39 (51\%; Time 1), 27 (36\%; Time 2), and 21 (28\%; Time 3) responded to surveys; and the overall prevalence of burnout were $7 / 39$ (18\%), 6/27 (22\%), and $7 / 21(33 \%)$, respectively. In detail, the prevalence of burnout at Time 1, Time 2, and Time 3 was 4/24 (17\%), 4/18 (22\%), and 5/12 (42\%) in PGY1 physicians and 3/15 (20\%), 2/9 (22\%), and 2/9 (22\%) in PGY2 physicians, respectively. The demographic characteristics of the resident physicians are shown in Table 1.

\section{Measurements}

The Maslach Burnout Index (MBI)

Burnout was measured using the Japanese translation of the Maslach Burnout Inventory-Human Services Survey (MBIHSS). This instrument was validated for measuring burnout by Higashiguchi and coleagues ${ }^{26}$ and consists of 22 items covering three domains: emotional exhaustion (EE), depersonalization (DP), and personal accomplishment (PA). Each item is answered on a 7-point Likert scale from "never" or 0 , to "daily" or 6. Because it is reported that PA was an independent variable, we defined an EE score of 27 or higher and a DP score of 10 or higher as being indicative of burnout in physicians; we, therefore, defined these individuals as "burnout positive."

\section{The Jefferson Scale of Empathy (JSE)}

In this study, we used the physician version of the Jefferson Scale of Physician Empathy (JSE) to measure the level of empathy in resident physicians. The scale includes 20 items answered on a 7-point Likert-type scale ( $1=$ strongly disagree, 7 = strongly agree). Higher scores indicate greater empathy, ${ }^{27}$, ${ }^{28}$ and the highest possible score is 140 .

\section{Patient Health Questionnaire (PHQ-9)}

We assessed the severity of depression using the 9-item $\mathrm{Pa}$ tient Health Questionnaire (PHQ-9). This is a commonly used means of screening for the presence and severity of depression. We used the Japanese translation of this scale, which was validated by Muramatsu and coleagues. ${ }^{22}$ The total scores of this scale range from 0 to 27; scores of 5-9 indicate mild depression, while scores of 10 or more suggest moderate or severe depression.

\section{Occupational and Socioeconomic Circumstances}

To assess the relationship between burnout and socioeconomic status such as living circumstances, residents were asked to provide their age, graduating school, living environment, workplace at the time of completing the questionnaires, self-reported average sleep time, and work hours in the nearest month. Because these resident physicians also engage in rotations in other university-affiliated community hospitals, they were asked about their training department and facility.

\section{Statistical analysis}

We examined the associations among the variables using Pearson's product moment correlation coefficient. We followed this with a linear regression analysis to further delineate the associations. The threshold for significance was $\mathrm{p}<$ 0.05 . All statistical analyses were conducted using SPSS Statistics 22.0 (IBM Japan, Ltd., Tokyo, Japan). 
Table 1. Demographic Characteristics of the Resident Physicians

\begin{tabular}{|c|c|c|c|c|c|c|}
\hline Variable & \multicolumn{2}{|c|}{$\begin{array}{l}\text { Time } 1 \\
(n=39)\end{array}$} & \multicolumn{2}{|c|}{$\begin{array}{l}\text { Time 2 } \\
(\mathrm{n}=27)\end{array}$} & \multicolumn{2}{|c|}{$\begin{array}{l}\text { Time } 3 \\
(\mathrm{n}=21)\end{array}$} \\
\hline \multirow[t]{2}{*}{ Mean Age (SD) } & \multicolumn{2}{|c|}{$26.0(2.2)$} & \multicolumn{2}{|c|}{$26.6(2.6)$} & \multicolumn{2}{|c|}{$27.4(2.7)$} \\
\hline & \multicolumn{2}{|c|}{$\mathrm{n}(\%)$} & \multicolumn{2}{|c|}{$\mathrm{n}(\%)$} & \multicolumn{2}{|c|}{$n(\%)$} \\
\hline \multicolumn{7}{|l|}{ Levels of training } \\
\hline PGY1 & \multicolumn{2}{|c|}{$24(61.5)$} & \multicolumn{2}{|c|}{$18(66.7)$} & \multicolumn{2}{|c|}{$12(57.1)$} \\
\hline PGY2 & \multicolumn{2}{|c|}{$15(38.5)$} & \multicolumn{2}{|c|}{$9(33.3)$} & \multicolumn{2}{|c|}{$9(42.9)$} \\
\hline Sex & PGY1 & PGY2 & PGY1 & PGY2 & PGY1 & PGY2 \\
\hline Male & $9(37.5)$ & $10(66.7)$ & $3(16.7)$ & $6(66.7)$ & $1(8.3)$ & $7(77.8)$ \\
\hline Female & $15(62.5)$ & $5(33.3)$ & $15(83.3)$ & $3(33.3)$ & $11(91.7)$ & $2(22.2)$ \\
\hline \multicolumn{7}{|l|}{ Graduating school } \\
\hline OU & $16(66.7)$ & $6(40.0)$ & $12(66.7)$ & $3(33.3)$ & $9(75.0)$ & $5(55.6)$ \\
\hline Others & $8(33.3)$ & $9(60.0)$ & $6(33.3)$ & $6(66.7)$ & $3(25.0)$ & $4(44.4)$ \\
\hline \multicolumn{7}{|l|}{ Living environment } \\
\hline Alone & $14(58.3)$ & $12(80.0)$ & $10(55.6)$ & $8(88.9)$ & $5(41.7)$ & $7(77.8)$ \\
\hline Alone with relatives nearby & $4(16.7)$ & 0 & $4(22.2)$ & 0 & $4(33.3)$ & 0 \\
\hline Together with someone & $6(25.0)$ & $3(20.0)$ & $4(22.2)$ & $1(11.1)$ & $3(25.0)$ & $2(22.2)$ \\
\hline \multicolumn{7}{|l|}{ Marital Status } \\
\hline Single & $20(83.3)$ & $15(100)$ & $15(83.3)$ & $9(100)$ & $9(75.0)$ & $1(11.1)$ \\
\hline Married & $4(16.7)$ & 0 & $3(16.7)$ & 0 & $3(25.0)$ & $8(88.9)$ \\
\hline \multicolumn{7}{|l|}{ Department of Training } \\
\hline Internal Medicine, OU & $12(50.0)$ & $1(6.7)$ & $4(22.2)$ & 0 & $4(33.3)$ & 0 \\
\hline Surgery and ED, OU & $3(12.5)$ & $1(6.7)$ & $1(5.6)$ & 0 & $2(16.7)$ & $1(11.1)$ \\
\hline Others, OU & $9(37.5)$ & $4(26.7)$ & $6(33.3)$ & $2(22.2)$ & $1(8.3)$ & $4(44.4)$ \\
\hline Internal Medicine, Away & 0 & $2(13.3)$ & $3(16.7)$ & $5(55.6)$ & $1(8.3)$ & $1(11.1)$ \\
\hline Surgery and ED, Away & 0 & $3(20.0)$ & $2(11.1)$ & 0 & $3(25.0)$ & $1(11.1)$ \\
\hline Others, Away & 0 & $4(26.7)$ & $2(11.1)$ & $2(22.2)$ & $1(8.3)$ & $2(22.2)$ \\
\hline \multicolumn{7}{|l|}{ Training Facility } \\
\hline $\mathrm{OUH}$ & $24(100)$ & $6(40.0)$ & $11(61.1)$ & $2(22.2)$ & $6(50.0)$ & $5(55.6)$ \\
\hline Community Hospital, Okayama & 0 & $9(60.0)$ & $7(38.9)$ & $4(44.4)$ & $5(41.7)$ & $1(11.1)$ \\
\hline Community Hospital, Others & 0 & 0 & 0 & $3(33.3)$ & $1(8.3)$ & $3(33.3)$ \\
\hline \multicolumn{7}{|l|}{ Preferred Specialty } \\
\hline Internal Medicine & $4(16.7)$ & $3(20.0)$ & $2(11.1)$ & $2(22.2)$ & 0 & $3(33.3)$ \\
\hline Surgery & 0 & $3(20.0)$ & 0 & $2(22.2)$ & 0 & $4(44.4)$ \\
\hline Others & $8(33.3)$ & $4(26.7)$ & $7(38.9)$ & $3(33.3)$ & $6(50.0)$ & $2(22.2)$ \\
\hline Not Determined & $12(50.0)$ & $5(33.3)$ & $9(50.0)$ & $2(22.2)$ & $6(50.0)$ & 0 \\
\hline Burnout & & & & & & \\
\hline Positive & $4(16.7)$ & $3(20.0)$ & $4(22.2)$ & $2(22.2)$ & $5(41.7)$ & $2(22.2)$ \\
\hline Negative & $20(83.3)$ & $12(80.0)$ & $14(77.8)$ & $7(77.8)$ & $7(58.3)$ & $7(78.8)$ \\
\hline Average working hours per week $[95 \% \mathrm{Cl}]$ & $\begin{array}{c}57.8 \\
{[54.7,61.0]}\end{array}$ & $\begin{array}{c}60.9 \\
{[54.1,67.7]}\end{array}$ & $\begin{array}{c}59.7 \\
{[53.7,65.6]}\end{array}$ & $\begin{array}{c}61.7 \\
{[49.7,73.6]}\end{array}$ & $\begin{array}{c}55.9 \\
{[48.5,63.4]}\end{array}$ & $\begin{array}{c}55.7 \\
{[46.8,64.8]}\end{array}$ \\
\hline Average hours of sleep [95\% Cl] & $\begin{array}{c}6.08 \\
{[5.84,6.32]}\end{array}$ & $\begin{array}{c}6.20 \\
{[5.61,6.79]}\end{array}$ & $\begin{array}{c}6.06 \\
{[5.76,6.35]}\end{array}$ & $\begin{array}{c}5.89 \\
{[5.32,6.46]}\end{array}$ & $\begin{array}{c}6.08 \\
{[5.48,6.69]}\end{array}$ & $\begin{array}{c}6.22 \\
{[5.75,6.70]}\end{array}$ \\
\hline PHQ-9 [95\% Cl] & $\begin{array}{c}4.04 \\
{[2.81,5.28]}\end{array}$ & $\begin{array}{c}4.40 \\
{[1.91,6.89]}\end{array}$ & $\begin{array}{c}5.67 \\
{[3.40,7.93]}\end{array}$ & $\begin{array}{c}5.67 \\
{[0.64,10.7]}\end{array}$ & $\begin{array}{c}5.58 \\
{[2.95,8.22]}\end{array}$ & $\begin{array}{c}4.56 \\
{[0.31,8.80]}\end{array}$ \\
\hline MBI-HSS [95\% Cl] & & & & & & \\
\hline Emotional Exhaustion (EE) & $\begin{array}{c}14.0 \\
{[10.3,17.6]}\end{array}$ & $\begin{array}{c}16.1 \\
{[11.3,21.0]}\end{array}$ & $\begin{array}{c}19.2 \\
{[13.5,25.0]}\end{array}$ & $\begin{array}{c}18.6 \\
{[11.3,25.8]}\end{array}$ & $\begin{array}{c}22.2 \\
{[15.5,28.8]}\end{array}$ & $\begin{array}{c}15.9 \\
{[9.05,22.7]}\end{array}$ \\
\hline Depersonalization (DP) & $\begin{array}{c}2.25 \\
{[0.91,3.59]}\end{array}$ & $\begin{array}{c}5.00 \\
{[2.08,7.92]}\end{array}$ & $\begin{array}{c}4.56 \\
{[2.77,6.34]}\end{array}$ & $\begin{array}{c}5.00 \\
{[1.78,8.22]}\end{array}$ & $\begin{array}{c}7.25 \\
{[3.30,11.2]}\end{array}$ & $\begin{array}{c}4.67 \\
{[2.46,6.87]}\end{array}$ \\
\hline Personal Accomplishment (PA) & $\begin{array}{c}25.9 \\
{[22.2,29.5]}\end{array}$ & $\begin{array}{c}29.2 \\
{[24.3,34.1]}\end{array}$ & $\begin{array}{c}25.6 \\
{[20.5,30.6]}\end{array}$ & $\begin{array}{c}30.9 \\
{[23.6,38.2]}\end{array}$ & $\begin{array}{c}28.1 \\
{[22.3,33.9]}\end{array}$ & $\begin{array}{c}26.0 \\
{[18.6,33.4]}\end{array}$ \\
\hline JSE $[95 \% \mathrm{Cl}]$ & $\begin{array}{c}116 \\
{[111,120]}\end{array}$ & $\begin{array}{c}112 \\
{[102,121]}\end{array}$ & Not a & essed & Not a & essed \\
\hline
\end{tabular}

Time 1, April 2017; Time 2, October 2017; Time 3, March 2018

SD: standard deviation; OU: Okayama University; ED: Emergency Department; OUH: Okayama University Hospital; PHQ-9: Patient Health Questionnaire-9; MBI-HSS: Maslach Burnout Inventory-Human Services Survey; EE: Emotional Exhaustion; DP: Depersonalization; PA: Personal Accomplishment; JSE: Jefferson Scale of Empathy 


\section{Results}

\section{Correlation between Burnout and Depression}

Table 2 shows the correlation between the burnout components (EE and DP) and depressive symptoms. Throughout the observational period, EE was significantly and positively correlated with PHQ-9 score $(\mathrm{r}=.615, \mathrm{p}<.001$ for Time $1 ; \mathrm{r}$ $=.706, \mathrm{p}<.001$ for Time $2 ; \mathrm{r}=.601, \mathrm{p}<.01$ for Time 3 ). By contrast, a consistently weak correlation was observed between the DP and PHQ-9 scores $(\mathrm{r}=.279, \mathrm{p}<.086$ for Time $1 ; \mathrm{r}=.047, \mathrm{p}<.817$ for Time $2 ; \mathrm{r}=.176, \mathrm{p}<.445$ for Time 3 ).

Table 2. Correlation between Burnout Dimensions and PHQ-9

\begin{tabular}{|c|c|c|c|c|c|c|}
\hline \multirow{3}{*}{ MBI-HSS } & \multicolumn{6}{|c|}{ PHQ-9 } \\
\hline & \multicolumn{2}{|c|}{ Time 1} & \multicolumn{2}{|c|}{ Time 2} & \multicolumn{2}{|c|}{ Time 3} \\
\hline & $r$ & $p$ & $r$ & $\mathrm{p}$ & $r$ & $p$ \\
\hline $\begin{array}{l}\text { Emotional } \\
\text { Exhaustion (EE) }\end{array}$ & 0.615 & $<0.001^{* * *}$ & 0.706 & $<0.001^{* * *}$ & 0.601 & $<0.01^{* *}$ \\
\hline $\begin{array}{l}\text { Depersonalization } \\
\text { (DP) }\end{array}$ & 0.279 & 0.086 & 0.047 & 0.817 & 0.176 & 0.445 \\
\hline
\end{tabular}

Time 1, April 2017; Time 2, October 2017; Time 3, March 2018

$r$, correlation coefficient, ${ }^{*} p<0.05,{ }^{* *} p<0.01,{ }^{* * *} p<0.001$

\section{Factors Correlated with Burnout and Depression}

We performed a linear regression analysis to clarify the factors affecting the EE and DP dimensions of burnout at Time 1. Table 3 and 4 display the results of this analysis. We initially conducted a univariate analysis to detect the significant factors and followed this with a multivariate analysis featuring the statistically significant variables from the univariate analysis. Being in PGY2 $(\beta=.318, \mathrm{p}=.049)$ and hours of sleep $(\beta=.330, p=.040)$ were significantly associated with DP score at baseline in the univariate analysis. In the multivariate analysis, only hours of sleep remained a significant factor and showed a positive relationship $(\beta=.309, \mathrm{p}=.047)$.

\section{Discussion}

This is the first exploratory pilot analyses of the associated factors of burnout in Japanese resident physicians with a special focus on its relationship with work hours. Compared to previous studies conducted in Japan, ${ }^{29}$ we focused on finding a correlation between burnout and socioeconomic factors, including occupational circumstances, in order to inform future interventions aimed at reducing burnout. We found that approximately 18 to $33 \%$ of resident physicians experienced burnout during the study period, which was relatively smaller than the prevalence in previous reports from other countries. ${ }^{1,6,10,14,30}$ However, considering the fact that one third of participants may be affected by burnout, it is crucial to develop burnout prevention measures for Japanese resident physicians.

We found that residents with longer sleep hours were more prone to high DP scores. Previous studies showed that insomnia $^{31-33}$ and lack of motivation ${ }^{34}$ were potential risk factors for burnout. On the other hand, higher empathy, ${ }^{35,36}$ and strong family support were reported to be protective factors. Contrary to our expectations, longer sleep hours had a significant impact on burnout in our study. Because of the small number of participants, the finding may not be clinically useful. Another possible explanation for this finding is that the loss of quality sleep might be a potential trigger for burnout, as previously reported in a cross-sectional study for nurses. ${ }^{37}$ We also found that resident physicians who had not chosen specialties at the beginning of the year were significantly more susceptible to high depersonalization at the end of the year. Because depersonalization is a psychological status characterized by callousness toward others, ${ }^{38}$ it is reasonable to speculate that anxiety and uncertainty about future career would influence residents' ability to deal with interpersonal relationships, which in turn may lead to depersonalization over time. Our data did not show any correlation between empathy and burnout. It may be due to high baseline empathy scores in the study participants,${ }^{27}$ and further research is needed to determine the effect of empathy on burnout in Japanese resident physicians.

There was a strong correlation between EE and depressive symptoms, which is consistent with the results of a previous study. ${ }^{39}$ Although there are still serious debates about whether burnout and depression are independent entities or not, ${ }^{18,21}$ it is reasonable to assume that persons who possess burnout traits have a greater tendency toward depression as well. Coupled with the high prevalence of depression among Japanese, ${ }^{40}$ these results suggest that we need to be more cautious than other countries with the overlap of burnout and depression in resident physicians. It may be important to perform depression and burnout screening at the same time in order to better treat affected individuals, utilizing existing epidemiologic data.

Our findings suggest that work hours were not significantly correlated with burnout. According to the Japanese MHLW, the average working hours per week of resident physicians was 53.7 hours plus 13.5 hours of on-call duty. ${ }^{41}$ As the average total working hours per week in all three surveys was between 55.9 to 60.3 hours, we assume that our data accurately reflect this working status of Japanese resident physicians. The lack of a relationship between work hours and burnout is contrary to a previous systematic review of 19 studies from 4 Western countries. ${ }^{42}$ Taken together, the findings indicate that only implementing overtime hours cap may be insufficient to prevent burnout in Japanese resident physicians. This aligns with the findings of a study on Chinese neurologists, in which, besides work hours, job content and satisfaction were crucial factors related to burnout. ${ }^{11}$ There are a number of pros and cons of work hour restrictions. A previous study found that work hour restrictions can decrease the quality of patient care and education. ${ }^{43}$ In 2003, the Accreditation Council for Graduate Medical Education (ACGME) implemented a rigid workhour restriction for resident physicians. ${ }^{44}$ 
Table 3. Univariate Linear Regression Analysis Predicting Burnout Components at the Baseline $(n=39)$

\begin{tabular}{|c|c|c|c|c|c|c|c|c|}
\hline \multirow{2}{*}{ Variable } & \multirow{2}{*}{ B } & \multirow{2}{*}{ SE } & \multicolumn{3}{|c|}{$\begin{array}{l}\text { Emotional Exhaustion } \\
\text { (EE) }\end{array}$} & \multicolumn{3}{|c|}{$\begin{array}{l}\text { Depersonalization } \\
\text { (DP) }\end{array}$} \\
\hline & & & $\beta$ & $\mathrm{p}$ & $\mathrm{B}$ & SE & $\beta$ & $\mathrm{p}$ \\
\hline $\begin{array}{l}\text { Age } \\
\text { Levels of Training }\end{array}$ & 0.096 & 0.647 & 0.024 & 0.883 & -0.058 & 0.317 & -0.030 & 0.857 \\
\hline Sex PGY2 (vs. PGY1) & 2.175 & 2.877 & 0.123 & 0.454 & 2.750 & 1.348 & 0.318 & $<0.05^{*}$ \\
\hline $\begin{array}{l}\text { Female (vs. Male) } \\
\text { Graduating School }\end{array}$ & -0.913 & 2.818 & -0.053 & 0.748 & -2.068 & 1.341 & -0.246 & 0.132 \\
\hline $\begin{array}{l}\text { OU (vs. others) } \\
\text { Living Environment }\end{array}$ & -2.241 & 2.820 & -0.130 & 0.432 & -0.393 & 1.393 & -0.046 & 0.779 \\
\hline $\begin{array}{l}\text { Alone } \\
\text { Alone with relatives nearby } \\
\text { Together with someone }\end{array}$ & $\begin{array}{c}\text { ref } \\
2.596 \\
-0.543\end{array}$ & $\begin{array}{l}4.772 \\
3.436\end{array}$ & $\begin{array}{c}0.092 \\
-0.027\end{array}$ & $\begin{array}{c}0.59 \\
0.875\end{array}$ & $\begin{array}{c}\text { ref } \\
-0.288 \\
1.295\end{array}$ & $\begin{array}{l}2.33 \\
1.678\end{array}$ & $\begin{array}{c}-0.021 \\
0.13\end{array}$ & $\begin{array}{l}0.902 \\
0.445\end{array}$ \\
\hline Marital Status & & & & & & & & \\
\hline $\begin{array}{l}\text { Single (vs. married) } \\
\text { Department of Training }\end{array}$ & 1.442 & 4.643 & 0.051 & 0.758 & 1.457 & 2.267 & 0.105 & 0.524 \\
\hline $\begin{array}{l}\text { Internal Medicine, OU } \\
\text { Surgery and ED, OU } \\
\text { Others, OU } \\
\text { Internal Medicine, Outside } \\
\text { Surgery and ED, Outside } \\
\text { Others, Outside }\end{array}$ & $\begin{array}{c}\text { ref } \\
-3.288 \\
-3.692 \\
2.462 \\
5.128 \\
2.962\end{array}$ & $\begin{array}{l}5.022 \\
3.445 \\
6.671 \\
5.625 \\
5.022\end{array}$ & $\begin{array}{r}-0.116 \\
-0.203 \\
0.063 \\
0.159 \\
0.105\end{array}$ & $\begin{array}{l}0.517 \\
0.292 \\
0.714 \\
0.369 \\
0.559\end{array}$ & $\begin{array}{l}\text { ref } \\
-3.038 \\
-0.769 \\
1.962 \\
4.462 \\
-1.038\end{array}$ & $\begin{array}{l}2.389 \\
1.639 \\
3.173 \\
2.676 \\
2.389\end{array}$ & $\begin{array}{c}-0.219 \\
-0.086 \\
0.103 \\
0.283 \\
-0.075\end{array}$ & $\begin{array}{l}0.212 \\
0.642 \\
0.541 \\
0.105 \\
0.667\end{array}$ \\
\hline Training Facility & & & & & & & & \\
\hline $\begin{array}{l}\text { Community Hospital (vs. OUH) } \\
\text { Preferred Specialty }\end{array}$ & 5.611 & 3.218 & 0.276 & 0.09 & 2.2 & 1.601 & 0.22 & 0.178 \\
\hline Internal Medicine & ref & & & & ref & & & \\
\hline Surgery & 6.571 & 6.061 & 0.204 & 0.286 & -2.952 & 3.011 & -0.187 & 0.334 \\
\hline Others & 4.821 & 4.177 & 0.259 & 0.256 & -1.536 & 2.075 & -0.168 & 0.464 \\
\hline Not Determined & 5.454 & 3.944 & 0.315 & 0.176 & -0.639 & 1.959 & -0.075 & 0.746 \\
\hline Working hours & 0.142 & 0.148 & 0.156 & 0.343 & 0.027 & 0.073 & 0.061 & 0.711 \\
\hline Hours of sleep & 0.279 & 1.822 & 0.025 & 0.879 & 1.796 & 0.843 & 0.33 & $<0.05^{*}$ \\
\hline JSE & -0.021 & 0.117 & -0.031 & 0.858 & -0.055 & 0.061 & -0.154 & 0.371 \\
\hline
\end{tabular}

Time 1, April 2017, Time 2, October 2017, Time 3, March 2018

$B=$ regression coefficient; $S E=$ standard error of regression coefficient; $\beta=$ standardized regression coefficient

While the restriction was considered to have improved patient safety and residents' mental health issues, it also had a negative impact on residents' graduate medical education and professional autonomy. ${ }^{45}$ In 2017, the ACGME relaxed these limits to allow interns to work a full 24-hour shift. ${ }^{46} \mathrm{In}$ Japan, the MHLW introduced a package of work-style reform bills to promote workers' health, which mainly involved capping overtime work hours. ${ }^{25}$ Although the Diet passed the law on June 29, 2018, for resident physicians, this bill cuts both ways: it may prevent overwork but may also harm their work quality and job satisfaction. The data of this study suggest that we need not to focus only on overtime hours cap, and policies need to focus also on maintaining job quality and satisfaction. Further data should be accumulated to determine how to address health problems in resident physicians.

Table 4. Multivariate Analysis of Factors Affecting DP Score $(\mathrm{n}=39)$

\begin{tabular}{lccccc}
\hline \multirow{2}{*}{ Variable } & \multicolumn{5}{c}{ Depersonalization (DP) } \\
\cline { 2 - 6 } & B & SE & $\beta$ & VIF & P \\
\hline Levels of training & & & - & & \\
$\quad$ PGY2 (vs. PGY1) & 2.554 & 1.296 & 0.295 & 1.005 & 0.056 \\
Hours of sleep & 1.679 & 0.815 & 0.309 & 1.005 & $<0.05^{*}$ \\
\hline
\end{tabular}

VIF: Variance Inflation Factor

This study has a few limitations. First, this was a pilot exploratory study, and it was conducted in a single teaching hospital. Thus, the results may not be generalized to other Int J Med Educ. 2019;10:129-135 populations. Second, of the resident physicians who were eligible to participate in this study, only 21 (28\%) to 39 (52\%) did so because of the voluntary nature of the survey. The results are therefore marred by potential selection bias, as the participants might have been more aware of the problems regarding burnout. Third, we cannot completely rule out the possibility of unobserved factors affecting the study results. Finally, because the data used for the analyses were collected from the participants via self-report, there might be some recall bias. Despite the preliminary nature of the results due to the small sample size, our study is significant in that it provides up-to-date data on burnout among Japanese resident physicians. The results highlight the future challenges in combating burnout. Although some interventions, such as yoga, holistic approaches, and stress reduction programs, have been reported as effective in preventing burnout, ${ }^{47-50}$ we require further insight into this area of study in relation to Japanese physicians. It is necessary to identify effective approaches to prevent burnout while taking Japanese culture into account. Future prospective observational studies are also required to validate our findings. To allow in-depth exploration into how Japanese resident physicians feel about their jobs, qualitative methods should be included in future studies.

\section{Conclusions}

Our findings suggest that approximately one fifth to onethird of Japanese resident physicians may experience 
burnout. The findings also suggest that work hour capping alone may be insufficient to prevent burnout among Japanese resident physicians. The potential implication for medical education and practice is that medical educators may need to consider not only work hour but also individual job quality and satisfaction to address burnout. It is recommended that future studies include qualitative methods to facilitate an in-depth exploration of the characteristics of burnout in Japanese resident physicians.

\section{Conflict of Interest}

The authors have no conflicts of interest to report.

\section{Reference}

1. Thomas NK. Resident burnout. JAMA. 2004;292(23):2880-2889. 2. Shanafelt TD, Mungo M, Schmitgen J, Storz KA, Reeves D, Hayes SN, et al. Longitudinal study evaluating the association between physician burnout and changes in professional work effort. Mayo Clin Proc. 2016;91(4):422-431. 3. Shanafelt TD, Dyrbye LN, West CP. Addressing physician burnout: the way forward. JAMA. 2017;317(9):901-2.

4. McClafferty H, Brooks AJ, Chen MK, Brenner M, Brown M, Esparham A, et al. Pediatric integrative medicine in residency program: relationship between lifestyle behaviors and burnout and wellbeing measures in first-year residents. Children (Basel). 2018;5(4):54.

5. Williford ML, Scarlet S, Meyers MO, Luckett DJ, Fine JP, Goettler CE, et al. Multiple-institution comparison of resident and faculty perceptions of burnout and depression during surgical training. JAMA Surg. 2018;153(8):705-711.

6. Shoimer I, Patten S, Mydlarski PR. Burnout in dermatology residents: a Canadian perspective. Br J Dermatol. 2017;178(1):270-271.

7. Sajjadi S, Norena M, Wong H, Dodek P. Moral distress and burnout in internal medicine residents. Can Med Educ J. 2017;8(1):e36-e43.

8. Lefor AK. Resident burnout. J Am Coll Surg. 2017;224(1):89.

9. Lebensohn P, Dodds S, Benn R, Brooks AJ, Birch M, Cook P, et al. Resident wellness behaviors: relationship to stress, depression, and burnout. Fam Med. 2013;45(8):541-549.

10. Doolittle BR, Windish DM, Seelig CB. Burnout, coping, and spirituality among internal medicine resident physicians. J Grad Med Educ. 2013;5(2):257-261.

11. Zhou X, Pu J, Zhong X, Zhu D, Yin D, Yang L, et al. Burnout, psychological morbidity, job stress, and job satisfaction in Chinese neurologists. Neurology. 2017;88(18):1727-1735.

12. Zhang M, Shi Y, Yang Y, Liu L, Xiao J, Guo T, et al. Burnout is associated with poor recovery of physical performance and low quality of life in patients after their first episode of acute coronary syndrome: a hospital-based prospective cohort study. Int J Cardiol. 2017;227:503-507.

13. Yuguero O, Ramon Marsal J, Esquerda M, Vivanco L, Soler-Gonzalez J. Association between low empathy and high burnout among primary care physicians and nurses in Lleida, Spain. Eur J Gen Pract. 2017;23(1):4-10.

14. Yang S, Meredith P, Khan A. Is mindfulness associated with stress and burnout among mental health professionals in Singapore? Psychol Health Med. 2017;22(6):673-679.

15. Whitebird RR, Solberg LI, Crain AL, Rossom RC, Beck A, Neely C, et al. Clinician burnout and satisfaction with resources in caring for complex patients. Gen Hosp Psychiatry. 2017;44:91-95.

16. Salyers MP, Bonfils KA, Luther L, Firmin RL, White DA, Adams EL, et al. The relationship between professional burnout and quality and safety in healthcare: a meta-analysis. J Gen Intern Med. 2017;32(4):475-482.

17. Panagioti M, Panagopoulou E, Bower P, Lewith G, Kontopantelis E, Chew-Graham C, et al. Controlled interventions to reduce burnout in physicians: a systematic review and meta-analysis. JAMA Intern Med. 2017;177(2):195-205.

18. Colville GA, Smith JG. The overlap between burnout and depression in ICU staff. Crit Care Med. 2017;45(10):e1102-e1103.

19. Bianchi R, Schonfeld IS, Laurent E. Physician burnout is better conceptualised as depression. Lancet. 2017;389(10077):1397-1398.
20. Wurm W, Vogel K, Holl A, Ebner C, Bayer D, Morkl S, et al. Depressionburnout overlap in physicians. PLoS One. 2016;11(3):e0149913.

21. Bianchi R, Schonfeld IS, Laurent E. Burnout-depression overlap: a review. Clin Psychol Rev. 2015;36:28-41.

22. Muramatsu K, Miyaoka H, Kamijima K, Muramatsu Y, Tanaka Y, Hosaka $\mathrm{M}$, et al. Performance of the Japanese version of the Patient Health Questionnaire-9 (J-PHQ-9) for depression in primary care. Gen Hosp Psychiatry. 2018;52:64-69.

23. Maeno T NA, Maeno T, Ozaki M, Kimura T, Tomita E, Sasahara S, Matsuzaki I. Resident stress in the new postgraduate clinical training system. Igaku Kyoiku. 2008;39(3):175-182.

24. Miyoshi R, Matsuo H, Takeda R, Komatsu H, Abe H, Ishida Y. Burnout in Japanese residents and its associations with temperament and character. Asian J Psychiatr. 2016;24:5-9.

25. The Council for the Realization of Work Style Reform, Ministry of Health, Labour and Welfare. The action plan for the realization of work style reform. 2017. [Cited 3 July 2018]; Available from: https://www.kantei.go.jp/jp/singi/hatarakikata/pdf/The_Action_Plan_for_the_Realization_of_Work_Style_Reform.pdf.

26. Higashiguchi K, Morikawa Y, Miura K, Nishijo M, Tabata M, Yoshita K, et al. The development of the Japanese version of the Maslach Burnout Inventory and the examination of the factor structure. Nihon Eiseigaku Zasshi. 1998;53(2):447-455.

27. Kataoka HU, Koide N, Ochi K, Hojat M, Gonnella JS. Measurement of empathy among Japanese medical students: psychometrics and score differences by gender and level of medical education. Acad Med. 2009;84(9):11921197.

28. Abe K, Niwa M, Fujisaki K, Suzuki Y. Associations between emotional intelligence, empathy and personality in Japanese medical students. BMC Med Educ. 2018;18(1):47.

29. Kanayama M, Suzuki M, Yuma Y. Longitudinal burnout-collaboration patterns in Japanese medical care workers at special needs schools: a latent class growth analysis. Psychol Res Behav Manag. 2016;9:139-146.

30. Lafreniere JP, Rios R, Packer H, Ghazarian S, Wright SM, Levine RB. Burned out at the bedside: patient perceptions of physician burnout in an internal medicine resident continuity clinic. J Gen Intern Med. 2016;31(2):203208.

31. Paice E, Hamilton-Fairley D. Avoiding burnout in new doctors: sleep, supervision and teams. Postgrad Med J. 2013;89(1055):493-494.

32. Wolf MR, Rosenstock JB. Inadequate sleep and exercise associated with burnout and depression among medical students. Acad Psychiatry. 2017;41(2):174-179.

33. Kawada T. Sleep, depression, and burnout in medical students: risk assessment. Acad Psychiatry. 2017;41(5):682-683.

34. Lyndon MP, Henning MA, Alyami H, Krishna S, Zeng I, Yu TC, et al. Burnout, quality of life, motivation, and academic achievement among medical students: a person-oriented approach. Perspect Med Educ. 2017;6(2):108114.

35. Wilkinson H, Whittington R, Perry L, Eames C. Examining the relationship between burnout and empathy in healthcare professionals: a systematic review. Burn Res. 2017;6:18-29.

36. Melnick ER, Powsner SM. Empathy in the time of burnout. Mayo Clin Proc. 2016;91(12):1678-1679.

37. Giorgi F, Mattei A, Notarnicola I, Petrucci C, Lancia L. Can sleep quality and burnout affect the job performance of shift-work nurses? A hospital cross-sectional study. J Adv Nurs. 2018;74(3):698-708.

38. West CP, Dyrbye LN, Satele DV, Sloan JA, Shanafelt TD. Concurrent validity of single-item measures of emotional exhaustion and depersonalization in burnout assessment. J Gen Intern Med. 2012;27(11):1445-1452.

39. West CP, Dyrbye LN, Erwin PJ, Shanafelt TD. Interventions to prevent and reduce physician burnout: a systematic review and meta-analysis. Lancet. 2016;388(10057):2272-2281.

40. Fushimi M, Saito S, Shimizu T. Prevalence of depressive symptoms and related factors in Japanese employees as measured by the Center for Epidemiologic Studies Depression Scale (CES-D). Community Ment Health J. 2013;49(2):236-242.

41. Health Policy Bureau, Ministry of Health, Labour and Welfare. Survey about current status of workload balance and intent of physician. [Cited 3 July 2018]; Available from: https://www.mhlw.go.jp/file/05-Shingikai10801000-Iseikyoku-Soumuka/0000161146.pdf. 
42. Busireddy KR, Miller JA, Ellison K, Ren V, Qayyum R, Panda M. Efficacy of interventions to reduce resident physician burnout: A systematic review. J Grad Med Educ. 2017;9(3):294-301.

43. Gopal R, Glasheen JJ, Miyoshi TJ, Prochazka AV. Burnout and internal medicine resident work-hour restrictions. Arch Intern Med. 2005; 165(22):2595-2600.

44. Sattar SP, Basith F, Madison J, Bhatia SC. New ACGME work-hour guidelines and their impact on current residency training practices. Acad Psychiatry. 2005;29(3):279-282.

45. Wolf SJ, Akhtar S, Gross E, Barnes D, Epter M, Fisher J, et al. ACGME clinical and educational work hour standards: Perspectives and recommendations from emergency medicine educators. West J Emerg Med. 2018;19(1):49-58.
46. Burchiel KJ, Zetterman RK, Ludmerer KM, Philibert I, Brigham TP, Malloy K, et al. The 2017 ACGME common work hour standards: Promoting physician learning and professional development in a safe, humane environment. J Grad Med Educ. 2017;9(6):692-696.

47. Alexander GK, Rollins K, Walker D, Wong L, Pennings J. Yoga for selfcare and burnout prevention among nurses. Workplace Health Saf. 2015;63(10):462-470; quiz 71.

48. Perez M. Holistic modalities \& self-care: hope for the prevention and recovery of professional burnout. Beginnings. 2016;36(4):8-9.

49. Stier-Jarmer M, Frisch D, Oberhauser C, Berberich G, Schuh A. The effectiveness of a stress reduction and burnout prevention program. Dtsch Arztebl Int. 2016;113(46):781-788.

50. Fortenberry K, Knox J, Hala SV. What do residents want for burnout prevention? ... Time. Acad Med. 2018;93(3):343-344. 